\title{
Research on the Training System of Applied Talents of College Sports Rehabilitation Professional Based on Maker Education
}

\author{
Mingming Gong, Wenyan Huang * \\ Hezhou University, Hezhou, Guangxi 542899 \\ *Corresponding Author: Wenyan Huang
}

Keywords: Maker Education, Sports Rehabilitation, Applied, Training System

\begin{abstract}
This paper systematically analyzes and explains the feasibility, implementation path, evaluation system, etc. of the maker education in the process of training the applied talents in college sports rehabilitation professional, by using literature research methods, logical analysis methods, and expert consultation methods. The implementation of maker education in college sports rehabilitation professional can promote the organic link between education chain and innovation chain; the implementation of maker education conforms to the concept of application-oriented college education and the goals of characteristic development; the implementation of maker education can more fully meet the needs of the community and promotes the development of students themselves. Its specific implementation path mainly includes: integrating the maker education into the teaching process of sports rehabilitation professional; infiltrating the maker mindset into all aspects of exercitation and training in and out of school in sports rehabilitation professional; implementing the whole-course tutoring system and focusing on the differential training of the talents; increasing the setting of maker course, and fully training applied talents. And from the theoretical basis, indicator design capabilities, program design capabilities, experimental operation capabilities, practical application capabilities, innovation capabilities, analysis and summary capabilities, design report capabilities, peer evaluation, third-party evaluation, etc. are trained to conduct a construction of its specific evaluation system.
\end{abstract}

\section{Introduction}

On December 19, 2017, the General Office of the State Council issued the "Several Opinions of the General Office of the State Council on Deepening the Integration of Production and Education" (hereinafter referred to as "Opinions"). The "Opinions", aiming at the incomplete adaptation of the current talent training supply side and the industry demand side, provided guidance opinions from the measures to promote the structural reforms on the supply side, such as deepening integration of production and education, promoting the education chain, linking the talents chain with the industrial chain, and the innovation chain. In order to make the training of sports rehabilitation professionals better connected with society, more needs should be considered in social needs, and more attention should be paid to the training of the creativity, innovation, application, and social adaptability of talents, which including the practical skills, the analytical skills, and the specific rehabilitation program design and application skills, etc. And maker education pays more attention to the cultivation of students' creative and practical skills, it is exactly the same as this.

\section{The Feasibility Analysis of Maker Education in Applied College Sports Rehabilitation Professional}

\subsection{The Implementation of maker education can promote the organic link between education chain and innovation chain}

In the 2014 Davos Forum, Prime Minister Li Keqiang mentioned the concept that "mass entrepreneurship and innovation" promotes the development of innovation and entrepreneurship. He pointed out that it is necessary to set off a new wave of "mass entrepreneurship" at home and form a 
new trend of "mandatory innovation." And a new trend based on innovation and entrepreneurship was subsequently formed. With the organization and implementation of the unique talent training model of application-type colleges and universities, the innovative and entrepreneurial environment, and the innovation and entrepreneurship at all levels, and with the construction and investment of "Popular Space" and "Innovation and Entrepreneurial Base", and the implementation of the "full-course mentoring system, university innovation and entrepreneurship education has entered an unprecedented period of rapid development. Sports rehabilitation professional is a major that pays attention to practical operation and application. In the cultivation process, the proportion of practical exercises, experiments and practical courses is high, and these applied courses must also include project learning, learning and accumulating experience in practice. Some experimental courses require 4-5 people to complete the training. This requires the development of students' collaborative learning skills, and needs to focus on adaptability and analytical skills. The practice patterns based on maker education are mainly for middle school, project learning and collaborative learning [1]. This echoes the training system of sports rehabilitation professional and coincides with it.

\subsection{The Implementation of Maker Education Conforms to the Concept of Application-oriented College Education and the Goals of Characteristic Development}

Various colleges and universities, especially local colleges, have gradually developed into applications.

These colleges and universities move forward in the exploration, gradually explore their own characteristics and manner of running a school, and constantly improve the training objectives. And the graduates who are exported to the society are gradually adapting to the needs of the society, the specialties that are set up constantly adapt to the development of the local economy, and these make the schools and employers reach a practical training model and training system for cooperation and mutual benefit; the sports rehabilitation professional follows the concept of "combination of physical medicine and healthy China" and continues to deepen the professional goals of promoting people's health through sports and physical fitness. It has unique effects and functions in helping disabled people such as trauma, chronic diseases, and the elderly and so on, and improving body functions. With the continuous improvement of people's living standards and health concepts, the social demand for sports rehabilitation talents has gradually increased. While the launch of maker education in the sports rehabilitation profession will inevitably increase the students' practical operation and flexibility, and make them more adaptable to the needs of society. The sports rehabilitation professional also has broad application prospects and development space, and it is not only suitable for setting application-type colleges and universities, but also in line with the application-oriented concept of running a university, it can better promote the integration and development of sports and leisure health and tourism specialties, and deepen the characteristics of running an applied college.

\subsection{The implementation of maker education can more fully meet the needs of the community and promote the development of students themselves}

The application-oriented colleges, with the main goal of training application senior talents, should give particular emphasis to the cultivation of the "applying" abilities and qualities, so that they have the theoretical knowledge, practical skills, and comprehensive quality, which are required to work in the high-tech requirements of related industries and occupations [3]. In order to meet the needs of the society, students of sports rehabilitation professional, must consolidate their professional foundations, systematically grasp basic theoretical knowledge, such as human anatomy, exercise physiology, basic knowledge of traditional Chinese medicine, etc.; skillfully use traditional Chinese medicine treatments, such as massage techniques, acupuncture, cupping, and scraping, and so on; and skillfully use comprehensive application capabilities, such as physical function assessment, physical training methods, exercise therapy, and musculoskeletal rehabilitation measures, etc.; and enhance the overall quality, these match the training objectives of application-oriented colleges. In fact, the maker education implementation system is also training 
advanced technical talents. In fact, the maker education implementation system is also to cultivate high-level technical talents with creative ability and practical application ability. Maker education is feasible in application-oriented college sports rehabilitation professional, and it can promote the common development of universities, students, and society.

\section{Measures for Cultivating Applied Talents of College Sports Rehabilitation Professional from Maker Education}

\subsection{Integrating the Maker Education into the Teaching Process of Sports Rehabilitation Professional}

Regardless of the characteristics of special skills and actual operation of the sports rehabilitation students, their ultimate goal is to provide rehabilitation programs, methods and recovery training for patients or rehabilitation groups, to keep them away from disease and sub-health status. However, the physical characteristics of the rehabilitation population are different, and it is also doomed that the rehabilitator must have a solid professional foundation and technology, and also have the ability to adapt and integrate, and this ability can be cultivated from the teaching process. Integrating the maker education into the teaching process of sports rehabilitation professional, allowing students to "learn in the process of doing and do it during the learning process", experience differences in rehabilitation groups, analyze differences in assessment indicators, and continuously summarize new rehabilitation programs and methods. These methods can be the increase, decrease and changes of rehabilitation types, the innovation of rehabilitation techniques, the modification of rehabilitation procedures, the improvement of rehabilitation methods, and the accumulation of practical experience in rehabilitation; the rehabilitation process is a complicated process, that requires training the specific implementation of different programs of the application and functions of the techniques, that will enable students to continuously improve their application capabilities.

\subsection{Infiltrating the Maker Mindset into all aspects of Exercitation and Training in and out of School in Sports Rehabilitation Professional}

The sports rehabilitation professional trains application talents who have a certain development potential, innovative spirit, and strong practical ability”. Experiments, internships, and practical training courses are important links for professional skills learning in sports rehabilitation, and also are important means and methods for cultivating students' practical ability [4]. While the maker education is better suited to the cultivation of this ability, and it can infiltrate the maker mindset into the process of experiments, internships, and training, and it also can cultivate students' creativity, divergent thinking and application ability. And, the best way to integrate is that when experimenting, practicing, constructing and choosing the training venue, more considerations are paid to whether it is suitable for the training needs of maker passengers and applied talents; in the course of experiments, internships, and training, applying maker mindset into all aspects, applying maker training measures into all aspects of exercitation and training meaningfully. During the process of internship and training, we should pay attention to the cultivation of the ability and the substantive content. The selection of the internship unit should highlight the diversity of features, and it should not only involve the rehabilitation medical department (or orthopedics) of a class-three (or equivalent) hospital, but also involve in sports rehabilitation centers and institutions. And it should also combine with the expertise of each training base, perform the selective and targeted internships or training, and focus on the cultivation of students' innovative ability and specialty.

\subsection{Implementing the Whole-course Tutoring System and Focusing on the Differential Training of the Talents}

In view of the professional characteristics of the sports rehabilitation profession, the implementation of the whole-course tutoring system can fully cultivate students' practical application ability. In addition, conducting in-school tutors and industry and corporate tutors to hire each other, and making students to understand the skills required by the company and truly grasp 
practical experience and capabilities. According to the previous investigation, the current domestic sports rehabilitation centers (institutions) have not yet formed a large scale, and there are fewer job vacancies. Every year, the number of interns required by each institution is about 4-6.If the school arranges internships and practical training in a unified way, it cannot be arranged in numbers. If the tutor alone contacts the sports rehabilitation center (institution), the internship plan can be completed in a small area, and targeted cultivation of "maker" can be carried out. Students trained in this way have strong practical abilities, and can better link up with the society, and this way can develop " high-creative, high-ability, high-skilled" applied talents to meet the needs of society for sports rehabilitation professionals. In the teaching process of the tutor's teaching courses and experimental courses, students can be arranged to participate in, for example, students can be arranged to participate in the classroom organization, preparation of experimental equipment and consumables, practical operation and application of the curriculum, these can actually cultivate students' creativity and practical ability. In addition, because of that during the implementation of the whole-course tutoring system, each tutor has students with a quantitative limit (about 1-10), so they can more fully identify the advantages and disadvantages of students, and thus can better cultivate differences and improve the quality of personnel training.

\subsection{Increasing the Setting of Maker Course, and Fully Training Applied Talents}

There are many types of innovation and entrepreneurship projects that can be practiced in sports rehabilitation. The "Opinions" clearly stated that: Actively supporting professional development in the social fields such as home economics, health, pensions, culture, and tourism, and so on, and promoting the construction of standardization, standardization, and branding. The sports rehabilitation professional directly corresponds to the health industry, so the level of support for the maker of sports rehabilitation professional at the national level continues to heat up. At present, the domestic sports rehabilitation centers (institutions) are basically established in first-tier cities, while the centers in second-line cities are relatively few, and in the third-tier cities are almost absent, so their scale and professionalism need to be improved, and sports rehabilitation professional happens at the right time. Only having professional ability and lacking of innovation and entrepreneurial ability, do not circumvent the various risks in entrepreneurship. And the cultivation of this ability must begin with the maker course, which includes the opening of entrepreneurship courses, such as the courses of college students' innovation and entrepreneurship foundation and related innovation and entrepreneurship training (eg SIYB, KAB), etc. These will be able to better cultivate students' ability of application and innovation and entrepreneurship, so that they can better connect with society.

\section{Construction of Evaluation System of Maker Education in the Process of Cultivating Applied Talents in College Sports Rehabilitation}

Maker education pays attention to process, understanding and work (output). Throughout the entire process, these links, that include the maker system, the maker environment, the maker curriculum, the maker space, the maker project, and the maker results, constitutes the overall framework of maker education, therefore, in the construction of its evaluation system, attention should be paid to all aspects. In addition, the "Opinions" clearly states that "actively supporting third-party institutions to carry out the performance evaluation of the integration of production and education, sounding the statistical evaluation system". Therefore, the proportion of third-party evaluation, should be involved in the construction of an applied talent evaluation system. In view of this, we have established a set of appraisal system for the training of applied talents of college sports rehabilitation professional, which is based on maker education. And its contents mainly include evaluation standards, evaluation grades, evaluation results, and proportions of sports rehabilitation students, as follows: (1) Theoretical basis: it includes understanding and mastery of the human basic anatomy, sports physiology, human development and analysis, musculature rehabilitation, rehabilitation assessment, sports therapy rehabilitation, sports injury rehabilitation, and physical fitness theory and methods, and its share is $15 \%$. (2) Indicator design capability: it 
mainly includes the application of common methods for the rehabilitation assessment of common chronic diseases, the assessment of specific indicators, and the design of index systems for rehabilitation training methods, and its share is 10\%; (3) Program design capability: it mainly includes the design of scientific, systematic, rational, and advanced programs, for patients or rehabilitation groups, the targeted rehabilitation assessment methods, and the targeted design of advanced physical training programs, and its share is 15\%; (4) Experimental operation ability: it includes the mastery of advanced experimental programs, experimental methods, experimental methods, etc., and the commonly experimental design of sports and health rehabilitation, and the protection of sports injuries (cardiopulmonary resuscitation, bandaging, palsy, forearm fracture splint fixation and joint loosening), musculature rehabilitation (shoulder peak impact disease, tennis elbow, joint replacement, Achilles tendon injury, lumbar disc herniation, and knee joint injury), neurological rehabilitation (spinal cord injury, cervical spondylopathy, and brachial plexus injury), etc., and its share is 15\%; (5) Practice and application ability: it includes the specific guidance and operation of differentiating rehabilitation technical operation and physical training methods, for different patients and rehabilitation groups, the experiment and test capabilities, and the operational proficiency of instruments (DMS, acupuncture, electrotherapy, functional training instruments, etc.) ) , etc., and its share is 10\%;(6) Innovation capability: it includes the application of innovative rehabilitation program design, and innovative rehabilitation training method implementation, etc., and its share is 5\%; (7) The overall ability to grasp: it includes the ability of analyzing and solving problems, and the ability of overall grasping the entire rehabilitation process, and its share is $10 \%$; (8) Design report capability: it includes that the report is complete, scientific, and reasonable, and its share is 5\%; (9) Classmates' mutual evaluation: it includes 3 5 classmates' average scores, and its share is 5\%; (10) Third-party evaluation: it includes the effectiveness evaluation of the integration of production and education among third-party institutions (including evaluations given by sports rehabilitation centers, medical institutions, etc.), and its share is $10 \%$. The overall scores are: Excellent, Good, Medium, Passed, Failed.

\section{Acknowledgements}

Fund: Hezhou University School-Level Teaching Reform Project (No.: hzxyjg201549) regarding to New Century Guangxi Higher Education and Teaching Reform Project (No.: 2016JGA346); New Century Guangxi Higher Education and Teaching Reform Project (No.: 2014JGB240)

\section{References}

[1] Yang Zhou. Workshop teaching based on the concept of maker education: practice style and frame design [J]. China Education Info, 2017(22): 71-73.

[2] Deng Zhang. Countermeasures to Optimize the Structure of Higher Education and Promote the Employment Rate of University Students[J]. Journal of Innovation and Enterprise Education, 2010(4):9-13. 